Check for updates

Cite this: RSC Adv., 2018, 8, 4314

\title{
Structural phase transition and bonding properties of high-pressure polymeric $\mathrm{CaN}_{3} \dagger$
}

\author{
Pugeng Hou, ${ }^{\text {a }}$ Lili Lian, ${ }^{\mathrm{b}}$ Yongmao Cai, ${ }^{a}$ Bao Liu, ${ }^{a}$ Bo Wang, ${ }^{a}$ Shuli Weic ${ }^{\mathrm{c}}$ and Da Li (D) *c
}

Received 1st November 2017 Accepted 22nd December 2017

DOI: $10.1039 / c 7 r a 11260 b$

rsc.li/rsc-advances

\begin{abstract}
Alkaline-earth metal polynitrides can be used as a type of starting materials in the synthesis of polymeric nitrogen, which is used as a potential high-energy-density material. The structural evolutionary behaviors of nitrogen in $\mathrm{CaN}_{3}$ were studied at the pressure up to $100 \mathrm{GPa}$ using a particle-swarm optimization structure search combining with density functional theory. Two new stable phases with $P \overline{1}$ and $C 2 / m$ space groups at the pressures of 26 and $60 \mathrm{GPa}$ were identified for the first time. Throughout the stable pressure range, these two structures are semiconductors and consist of the $\mathrm{N}$ atoms in $\mathrm{sp}^{2}$-hybrid states. To the best of our knowledge, this is the first time an $\mathrm{N}_{6}$ chain is reported in case of alkalineearth metal polynitrides. The stable polynitrogen compounds and polymeric nitrogen as high-energydensity materials have potential applications. The present results open a new possible avenue to synthesize high-energy-density polynitrogen.
\end{abstract}

\section{Introduction}

To discover and synthesize environmentally harmless high energy-density materials (HEDMs) is becoming increasingly important at present. Among the myriad HEDMs, the polynitrogen compounds are of significant interest due to their particularly high energy and high enthalpy of formation among other features. ${ }^{1-9}$ Nitrogen exists in form of $\mathrm{N}_{2}$ molecules in nitrogen gas with $\mathrm{N} \equiv \mathrm{N}$ bonds. It is significantly interesting if the abundant $\mathrm{N}_{2}$ molecules can be transformed into polynitrogen with $\mathrm{N}-\mathrm{N}$ bonds and $\mathrm{N}=\mathrm{N}$ bonds. The $\mathrm{N}-\mathrm{N}$ and $\mathrm{N}=\mathrm{N}$ or $\mathrm{N} \equiv \mathrm{N}$ bonds have large energy difference between them, which can be used in industrial applications. Although numerous theoretical studies predicting that some highpressure nitrogen phases might be stable, ${ }^{7,10}$ it was not until 2004 that the cubic gauche phase of nitrogen (cg-N) was experimentally synthesized using high pressure and high temperature treatment $(110 \mathrm{GPa}, 2000 \mathrm{~K}) .^{11}$ It has been predicted that the single-bond phase of solid nitrogen has more than three times higher energy storage capacity than that of the most powerful energetic materials. ${ }^{12}$

Recently, metal azides, as a type of precursors, have been proposed to be used in the formation of polymeric nitrogen. One feasible approach to obtain such polymeric nitrogen phases is to form nitrogen-rich alloys with other elements.

${ }^{a}$ College of Science, Northeast Electric Power University, No. 169 Changchun Road, Jilin City, 132012, P. R. China. E-mail: houpugeng@126.com

${ }^{b}$ The First Hospital of Jilin University, Changchun, 130021, P. R. China

'State Key Laboratory of Superhard Materials, College of Physics, Jilin University, Changchun, 130012, P. R. China. E-mail: dali@jlu.edu.cn

$\dagger$ Electronic supplementary information (ESI) available. See DOI: $10.1039 / \mathrm{c} 7 \mathrm{ra} 11260 \mathrm{~b}$
Such "chemical precompression" may reduce the pressure of polymerization significantly. Theoretical and experimental studies are inspired by elusive polymeric nitrogen and considerable progress has been achieved in the exploration of stable nitrogen-rich compounds. Recently, metal azides can be used as the starting materials to synthesize numerous types of potential high-energy-density materials because the synthesis pressure of metal azides is potentially lower than that of pure nitrogen gas. Over the years, various metal azides have been proposed in numerous experimental and theoretical studies, for example, $\mathrm{LiN}_{3},{ }^{13-16} \mathrm{LiN}_{5},{ }^{13} \mathrm{NaN}_{3},{ }^{17-21}$ $\mathrm{KN}_{3},{ }^{20,22-27} \mathrm{CsN}_{3},{ }^{23,28}$ and $\mathrm{AlN}_{3}{ }^{29}$ Moreover, $\mathrm{N}_{2} \mathrm{H},{ }^{30,31} \mathrm{C}-\mathrm{N}$ system, ${ }^{32,33}$ S-N system, ${ }^{34}$ and the $\mathrm{P}-\mathrm{N}$ system $^{35}$ are also studied as high-energy materials. These successes precipitate an increasing interest in searching for other forms of stable polynitrogen in metal polynitrogen compounds in the recent years.

The chemistry of calcium is relatively underdeveloped compared to that of its analogues (Be, $\mathrm{Mg}$, Sr, and $\mathrm{Ba}$ ). Recently, we theoretically explored the phase diagram of the $\mathrm{Mg}-\mathrm{N}$ system at the pressures ranging from 0 to $100 \mathrm{GPa}^{36}$ and discovered a series of new compounds in this family, including $\mathrm{Mg}_{2} \mathrm{~N}_{3}$, $\mathrm{MgN}, \mathrm{MgN}_{3}, \mathrm{MgN}_{4}$, and $\mathrm{MgN}_{5}$. The predicted compounds contain a rich variety of polynitrogen forms ranging from small molecules $\left(\mathrm{N}_{2}, \mathrm{~N}_{3}, \mathrm{~N}_{4}\right.$, and $\left.\mathrm{N}_{6}\right)$ to the extended nitrogen chains. Alkaline-earth metal calcium and alkali metal potassium are adjacent in the periodic elements table. In addition, calcium can exhibits a similar chemical activity as compared to that of alkali metal element potassium. Thus, we can expect that mixing reactive calcium element with nitrogen will realize more diverse structures that obtain higher energy densities of the products. Therefore, a study of calcium polynitride would help 
to theoretically investigate more promising high-energy materials among alkaline-earth metal polynitrides. High pressuretreatment has emerged as a powerful tool to investigate the physical and chemical behaviours of materials and it can be a crucial thermodynamic parameter. This study has led to the synthesis of new and unexpected products. A new orthorhombic phase was predicted as the thermodynamic ground state of $\mathrm{CaN}_{2}$, which has considerably lower energy than that of the synthesized phase as well as the theoretical models considered earlier. ${ }^{37}$ Zhang et al. identified a tetragonal $\mathrm{Ca}_{2} \mathrm{~N}$ structure under high pressures, giving an excellent agreement between the theoretical and experimental XRD data. ${ }^{38}$ Recently, Zhu et al. theoretically explored the phase diagram of the $\mathrm{Ca}-\mathrm{N}$ system, including $\mathrm{Ca}_{2} \mathrm{~N}_{3}, \mathrm{CaN}, \mathrm{CaN}_{3}, \mathrm{CaN}_{4}$, and $\mathrm{CaN}_{5}{ }^{39}$ The predicted $\mathrm{CaN}_{x}$ compounds contained a rich variety of polynitrogen forms ranging from small molecules $\left(\mathrm{N}_{2}, \mathrm{~N}_{4}, \mathrm{~N}_{5}\right.$, and $\left.\mathrm{N}_{6}\right)$ to the extended chains $\left(\mathrm{N}_{\infty}\right)$. The $\mathrm{CaN}_{x}$ crystals with polynitrogens were expected to be highly exothermic, making them as the potential high-energy-density materials. The newly predicted $\mathrm{CaN}_{3}$ phase was calculated to become thermodynamically stable under low pressure ( $P=8 \mathrm{GPa})$. At $8 \mathrm{GPa}, \mathrm{CaN}_{3}$ has an orthorhombic Pmma structure.

In the present study, the possible formation and the stability of the polymeric nitrogen compounds were investigated in the binary $\mathrm{CaN}_{3}$ under high pressure. The structure searches for the stable $\mathrm{CaN}_{3}$ compound were performed using an unbiased structure prediction method based on particle-swarm optimization algorithm in conjunction with density-functional calculations. Then, the electronic properties and chemical bonding of the identified $\mathrm{Ca}-\mathrm{N}$ compounds were investigated systematically in order to study the properties and the potential applications of the binary $\mathrm{CaN}_{3}$ compound as high energy-density materials. The lattice dynamics, structural stability, electronic structure, and bonding nature were studied, providing more insights into the mechanism of the pressure-induced physical properties. The understanding of metal-nitrogen interactions and the bonding nature in these polynitrogens is of great importance to the research on nitrogen chemistry.

\section{Computation details}

The crystal structure prediction for the $\mathrm{CaN}_{3}$ system via global minimization of free energy surfaces was performed through CALYPSO code, which has demonstrated recent success in predicting the high-pressure structures of numerous substances from the elemental to binary and ternary compounds and validated with various known compounds..$^{40-42}$ The lowest-energy structures for $\mathrm{CaN}_{3}$ were determined at 0,20 , 50,80 , and $100 \mathrm{GPa}$ with the systems containing one to six formula units (f.u.) in the simulation cell. The underlying $a b$ initio structural relaxations and electronic band structural calculations for $\mathrm{CaN}_{3}$ were performed in the framework of the density functional theory (DFT) within generalized gradient approximation Perdew-Burke-Ernzerhof (GGA-PBE) ${ }^{43}$ as implemented in the VASP (Vienna ab initio simulation package) code. ${ }^{44}$ The projector-augmented wave (PAW) $)^{45}$ pseudopotentials are used from the VASP potential library. The $3 \mathrm{~s}^{2} 3 \mathrm{p}^{6} 4 \mathrm{~s}^{2}$ for
$\mathrm{Ca}$ and $2 \mathrm{~s}^{2} 2 \mathrm{p}^{3}$ for $\mathrm{N}$ were treated as the valence states. The computational parameters were tested such that the energy calculations were well converged to better than $1 \mathrm{meV}$ per atom. A plane-wave energy cutoff of $620 \mathrm{eV}$ and appropriate Monkhorst-Pack ${ }^{46} k$-meshes ( $k$-points grid of $0.03 \AA^{-1}$ ) were used in the Brillouin zone. We calculated the net charge based on Bader analysis. ${ }^{47,48}$ The supercell method with PHONOPY code was used to calculate the phonon frequencies for all structures. ${ }^{49} \mathrm{In}$ addition, we used the DFT + D2 approach, ${ }^{50-52}$ which is a simple and efficient way to approximately account for the long-range van der Waals interactions. In this method, the sum of the induced dipole-dipole interactions $\left(E_{\text {disp }}\right)$ was added to the selfconsistent total energy calculated within Kohn-Sham DFT ( $E_{\mathrm{KS}-}$ DFT), $E_{\mathrm{DFT}+\mathrm{D} 2}=E_{\mathrm{KS}-\mathrm{DFT}}+E_{\text {disp. }}$. We choose a cutoff radius of 30 Åfor the van der Waals interactions and the global scaling parameter $s_{6}$ was set to 0.75 .

\section{Results and discussions}

\subsection{Phase stability}

The most favorable $\mathrm{Ca}-\mathrm{N}$ compounds obtained in the structure search at various pressures are presented in Fig. 1a. ${ }^{39}$ For the energetically most favorable $\mathrm{CaN}_{3}$ structures, the calculated formation enthalpies $\Delta H_{\mathrm{f}}$ in the pressure range from 0 to $100 \mathrm{GPa}$ are shown in Fig. 1b. The $\Delta H_{\mathrm{f}}$ of each $\mathrm{CaN}_{3}$ structure was calculated by $\Delta H_{\mathrm{f}}\left(\mathrm{CaN}_{3}\right)=H\left(\mathrm{CaN}_{3}\right)-H(\mathrm{Ca})-3 H(\mathrm{~N})$ at $T=$ $0 \mathrm{~K}$. The known solid calcium $(\alpha, \beta$, and $\gamma$ phase) and solid nitrogen $\left(\alpha-, P b c n-, P 2 / c^{-}\right.$, and cg-phases) ${ }^{53}$ were used as the reference structures. These structures are energetically most favorable in their corresponding stable pressure ranges. In order to determine the phase transition pressure for the predicted $\mathrm{CaN}_{3}$, we have plotted out the enthalpy curves relative to the ambient pressure $P \overline{1}-\mathrm{CaN}_{3}$. The enthalpies of the most energetically competitive structures are compared over the pressure range from $0 \mathrm{GPa}$ to $100 \mathrm{GPa}$ as shown in Fig. 1. The most stable structure has a monoclinic phase with $P \overline{1}$ symmetry from $26 \mathrm{GPa}$ up to $40 \mathrm{GPa}$, which is then replaced by a lowerenthalpy $C 2 / c$ structure that has been proposed by Zhu et al. ${ }^{39}$ With further compression above $60 \mathrm{GPa}$, another monoclinic phase, $C 2 / m-\mathrm{CaN}_{3}$, becomes the most thermodynamically stable phase and remains the lowest-enthalpy phase up to $100 \mathrm{GPa}$. Since the two low-pressure $P \overline{1}-\mathrm{CaN}_{3}$ and high-pressure $C 2 / \mathrm{m}$ $\mathrm{CaN}_{3}$ phases are novel for alkali-earth metal polynitrides and metal azides, the investigation about the properties of the two high-pressure phases in detail is essential. The ambientpressure decomposition of $P \overline{1}-\mathrm{CaN}_{3}$ and $C 2 / m-\mathrm{CaN}_{3}$ to $\mathrm{CaN}_{2}$ and $\mathrm{N}_{2}$ are estimated to release $1.04 \mathrm{eV}$ and $1.34 \mathrm{eV}$ energy per formula unit (f.u.), which corresponds to an energy density of approximately $1.14 \mathrm{~kJ} \mathrm{~g}^{-1}$ and $1.47 \mathrm{~kJ} \mathrm{~g}^{-1}$, respectively. Such high energy content can establish that $\mathrm{CaN}_{3}$ is indeed a high energy density material. It can replace modern high explosives, such as TATB, RDX, and HMX, which typically have energy densities ranging from 1 to $3 \mathrm{~kJ} \mathrm{~g}^{-1} .^{54}$ Thus, we may find their applications as a high energy materials. This study, therefore, represents an exciting prediction and can hopefully encourage the experimental efforts in their synthesis. 

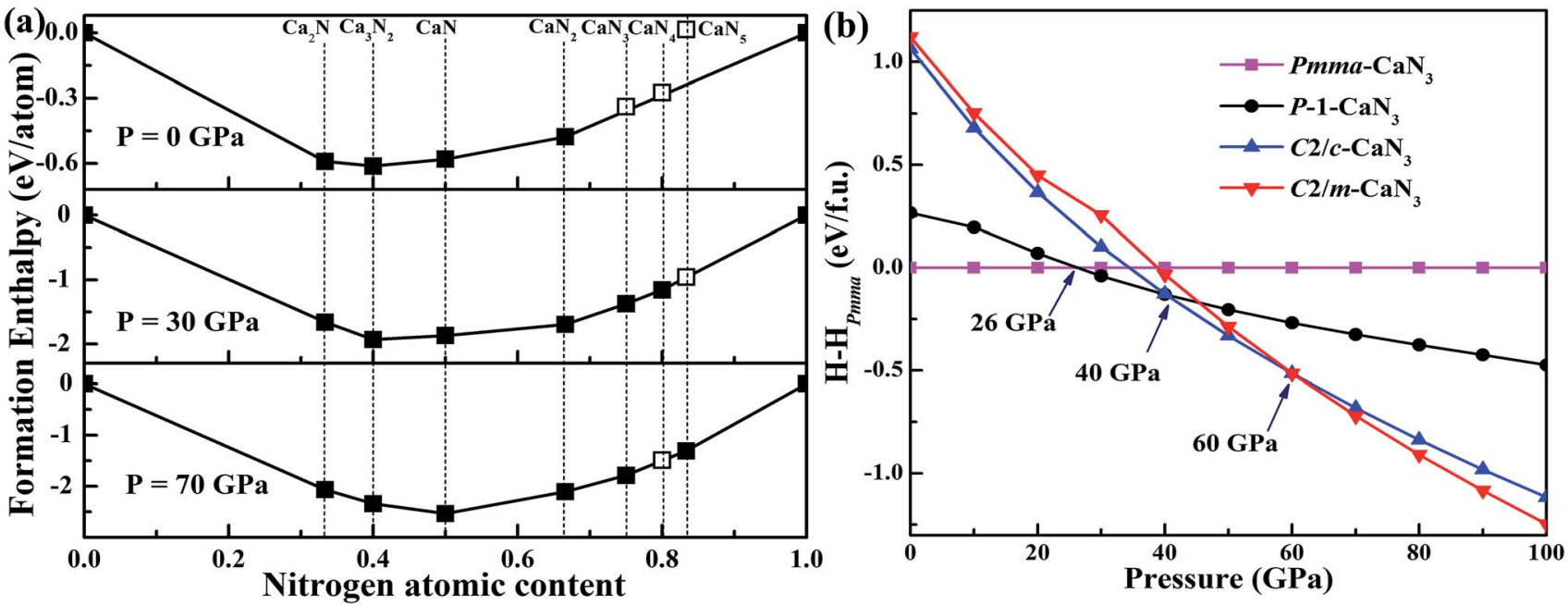

Fig. 1 (a) Relative enthalpies of the formation of $\mathrm{Ca}-\mathrm{N}$ phases with respect to solid calcium and nitrogen. Reference to the results of Zhu et al. ${ }^{37}$ (b) Relative enthalpies of the $\mathrm{CaN}_{3}$ relative to the Pmma-CaN 3 calculated by the DFT + D2 approach as a function of pressure.

The calculated relations of phonon dispersion of lowpressure $P \overline{1}-\mathrm{CaN}_{3}$ and high-pressure $C 2 / m-\mathrm{CaN}_{3}$ also confirmed their mechanical and dynamical stability as shown in Fig. 2. No imaginary phonon mode can be observed, which

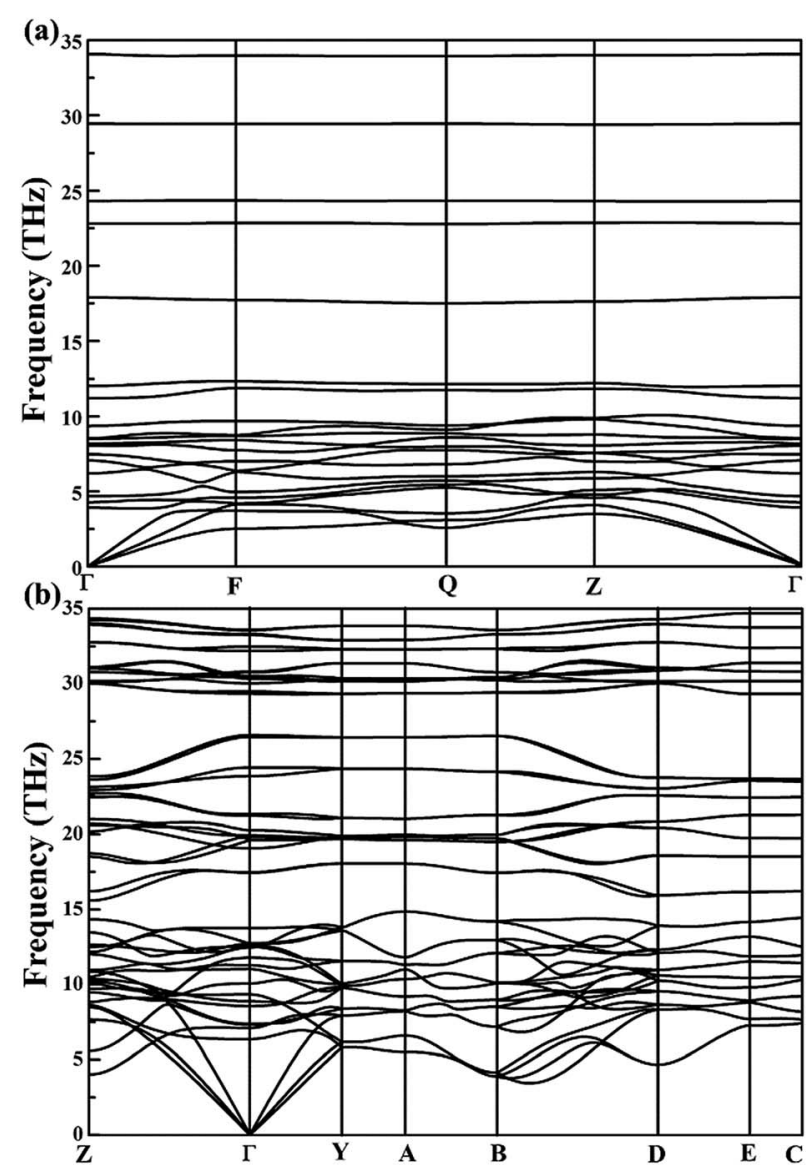

Fig. 2 Phonon dispersion curves for (a) $P 1-\mathrm{CaN}_{3}$ at ambient pressure and (b) $\mathrm{C} 2 / m-\mathrm{CaN}_{3}$ at $60 \mathrm{GPa}$. proves clearly their lattice dynamical stability. Under some kinetic regimes at ambient conditions, the calcium polynitride $\mathrm{CaN}_{3}$ also has the possibility of stabilizing. Advantageously, these two structures $P \overline{1}-\mathrm{CaN}_{3}$ and $C 2 / m-\mathrm{CaN}_{3}$ are mechanically stable at ambient conditions and they may possibly quench under an ambient pressure.

Another important indicator of the existence of these structures is their mechanical stability. According to the BornHuang criterion, ${ }^{55}$ it was found that $P \overline{1}-\mathrm{CaN}_{3}$ and $C 2 / m-\mathrm{CaN}_{3}$ were mechanically stable at an ambient pressure and $60 \mathrm{GPa}$. In order to be used in potential technological and industrial applications, the understanding of the mechanical properties (elastic constant and anisotropy) of the predicted $\mathrm{CaN}_{3}$ structures is important. The elastic constants $\left(C_{i j}\right)$, bulk modulus $(B)$, shear modulus $(G)$, Young's modulus $(Y)$, and Poisson's ratio $(\nu)$ of the $P \overline{1}-\mathrm{CaN}_{3}$ and $C 2 / m$ - $\mathrm{CaN}_{3}$ structures are summarized in Table 1 . The elastic constants for both $P \overline{1}-\mathrm{CaN}_{3}$ and $C 2 / m-\mathrm{CaN}_{3}$ were calculated using the strain-stress method. For the monoclinic crystals, if they are mechanically stable, the elastic constants need to satisfy the following mechanical criteria:

$$
\begin{gathered}
C_{11}>0, C_{22}>0, C_{33}>0, C_{44}>0, C_{55}>0, C_{66}>0 \\
{\left[C_{11}+C_{22}+C_{33}+2\left(C_{12}+C_{13}+C_{23}\right)\right]>0} \\
\left(C_{33} C_{55}-C_{35}{ }^{2}\right)>0,\left(C_{44} C_{66}-C_{46}{ }^{2}\right)>0,\left(C_{22}+C_{33}-2 C_{23}\right)>0 \\
{\left[C_{22}\left(C_{33} C_{55}-C_{35}{ }^{2}\right)+2 C_{23} C_{25} C_{35}-C_{23}{ }^{2} C_{55}-C_{23}{ }^{2} C_{33}\right]>0 .}
\end{gathered}
$$

As illustrated in Table 1, we can observe that the elastic constants for the monoclinic $P \overline{1}-\mathrm{CaN}_{3}$ and $C 2 / m-\mathrm{CaN}_{3}$ structures satisfy the above conditions, which implies that the two phases, $P \overline{1}-\mathrm{CaN}_{3}$ and $C 2 / m-\mathrm{CaN}_{3}$, are elastically stable at ambient pressure and $60 \mathrm{GPa}$, respectively. Hence, the calculations indicate that $P \overline{1}-\mathrm{CaN}_{3}$ and $C 2 / m-\mathrm{CaN}_{3}$ are elastically stable. It is valuable to be mentioned that the bulk modulus for the $C 2 / m-\mathrm{CaN}_{3}$ phase, which was calculated from the elastic 
Table 1 Calculated elastic constants $C_{i j}$ 's $(G P a)$, bulk modulus $\left(B_{0}\right)$, shear modulus $(G)$, Young's modulus $(Y)$, and Poisson's ratio $(\nu)$ for the $P \overline{1}-$ $\mathrm{CaN}_{3}$ and $\mathrm{C} 2 / \mathrm{m}-\mathrm{CaN}$ structures under $P=0 \mathrm{GPa}$ and $60 \mathrm{GPa}$

\begin{tabular}{|c|c|c|c|c|c|c|c|c|c|c|c|c|c|c|c|}
\hline & $C_{11}$ & $C_{22}$ & $C_{33}$ & $C_{44}$ & $C_{55}$ & $C_{66}$ & $C_{12}$ & $C_{13}$ & $C_{23}$ & $C_{35}$ & $C_{46}$ & $B_{0}$ & $G$ & $Y$ & $\nu$ \\
\hline$P \overline{1}-\mathrm{CaN}_{3}$ & 216 & 208 & 122 & 64 & 50 & 86 & 77 & 46 & 82 & -1.4 & -5.5 & 101 & 59 & 149 & 0.25 \\
\hline$C 2 / m-\mathrm{CaN}_{3}$ & 546 & 546 & 596 & 246 & 193 & 190 & 235 & 194 & 233 & -0.3 & 18.0 & 333 & 191 & 481 & 0.26 \\
\hline
\end{tabular}

constants, is $333 \mathrm{GPa}$ (Table 1 ). Hence, the $C 2 / m-\mathrm{CaN}_{3}$ phase is also a high-incompressibility material.

\subsection{Structural features}

$\mathrm{CaN}_{3}$ is predicted to take the monoclinic $P \overline{1}$ space group at $0 \mathrm{GPa}$ as shown in Fig. 3a. The lattice constants of the predicted $P \overline{1}-\mathrm{CaN}_{3}$ are $a=4.744 \AA, b=5.307 \AA, c=3.182 \AA, \alpha=76.70^{\circ}, \beta=$ $97.94^{\circ}$, and $\gamma=80.80^{\circ}$ at $P=30 \mathrm{GPa}$. Four inequivalent atoms occupy the crystallographic structure: $\mathrm{Ca}$ at $2 i(0.696,0.198$, $0.077), \mathrm{N} 1$ at $2 i(0.307,0.321,0.399), \mathrm{N} 2$ at $2 i(0.140,0.517$, $0.507)$ and $\mathrm{N} 3$ at $2 i(0.204,0.136,0.262)$ positions. The $C 2 / \mathrm{m}^{-}$ $\mathrm{CaN}_{3}$ crystal is predicted to become energetically stable near $70 \mathrm{GPa}$. This phase has the optimized lattice parameters: $a=$ 8.125 $\mathrm{A}, b=5.175 \AA, c=3.206 \AA, \alpha=90.0^{\circ}, \beta=67.2^{\circ}$, and $\gamma=$ $90.0^{\circ}$. The atomic positions are as follows: Ca atoms at $4 i(0.673$, $0.00,0.185)$ and $\mathrm{N} 1$ atom at $8 j(0.422,0.275,0.204), \mathrm{N} 2$ atom at $4 i(0.085,0.0,0.542)$.

The potential energy storage capabilities for the two predicted new $P \overline{1}-\mathrm{CaN}_{3}$ and $C 2 / m-\mathrm{CaN}_{3}$ have a close relationship with their structure motifs and the patterns of the $\mathrm{N}$ atoms. Fig. 3a shows the crystal structure of $P \overline{1}-\mathrm{CaN}_{3}$, in which the $\mathrm{N}$ atoms adopt the $\mathrm{N}_{6}$ chain in the (001) plane. The $\mathrm{N}$ atoms in this structure are $\mathrm{sp}^{2}$-hybridized containing a high content of $\mathrm{N}-\mathrm{N}$ single bonds in $P \overline{1}-\mathrm{CaN}_{3}$. To the best of our knowledge, this is the first time the $\mathrm{N}_{6}$ chain is reported in case of alkaline-earth metal polynitrides. In addition, the bond lengths of $\mathrm{N}-\mathrm{N}$ are from $1.323 \AA$ to $1.352 \AA$, which are greater than that of an $\mathrm{N}=\mathrm{N}$ bond $(1.20 \AA)$ and shorter than that of an $\mathrm{N}-\mathrm{N}$ single bond (1.45 $\AA)$. This intermediate distance has a connection with the
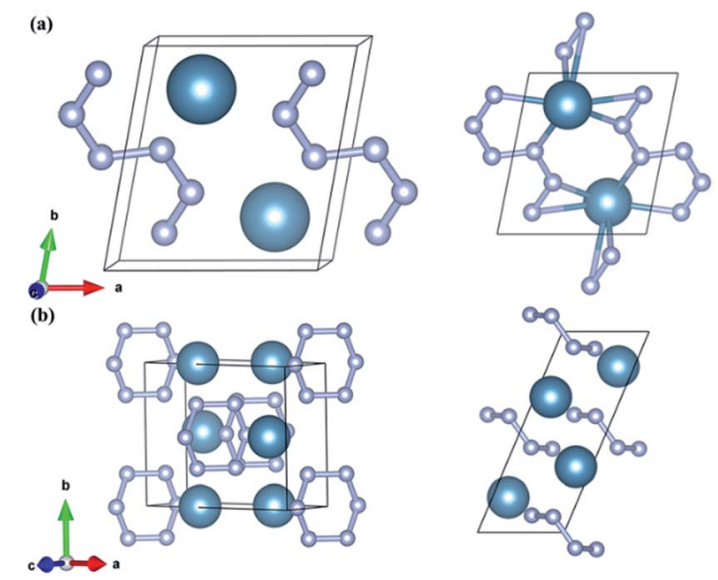

Fig. 3 Crystal structures of the predicted stable (a) $P 1-\mathrm{CaN}_{3}$ and (b) $\mathrm{C} 2 / \mathrm{m}-\mathrm{CaN}_{3}$. The large and small spheres denote calcium and nitrogen atoms, respectively. electron delocalization, in which the $\pi$-electrons are distributed equally among six the $\mathrm{N}$ atoms. Each $\mathrm{N}$ atom of the $\mathrm{N}_{6}$ chain is coordinated with two nearest $\mathrm{Ca}$ atoms and each $\mathrm{Ca}$ atom is sixcoordinated with nearby $\mathrm{N}$ atoms $\left(d_{\mathrm{Ca}-\mathrm{N}}=2.51 \AA\right.$ at $\left.0 \mathrm{GPa}\right)$. With an increase in the pressures to $60 \mathrm{GPa}$, a promising monoclinic $C 2 / m$ phase including partial single $\mathrm{N}-\mathrm{N}$ bonds was identified for $\mathrm{CaN}_{3}$. The high-pressure $C 2 / m-\mathrm{CaN}_{3}$, interestingly, has a puckered layer-like structure with six $\mathrm{N}$ atoms forming a nonplanar $\mathrm{N}_{6}$ ring as shown in Fig. 3 b. The hexagonal $\mathrm{N}_{6}$ ring has been researched in numerous theoretical studies, but they are not satisfactory. ${ }^{56,57}$ By adding the coordinate-covalent bonds from oxygen, the isoelectronic with benzene $\mathrm{N}_{6}$ ring can be formed..$^{58}$ Moreover, the planar $\mathrm{N}_{6}$ ring can be remarkably enhanced using the incorporation of a metal atom in these metal- $\mathrm{N}_{6}$ molecule compounds. ${ }^{59}$ We can obtain the $\mathrm{N}_{6}$ rings by theoretical simulation calculation in the bulk materials. This shows that additional metal atoms can play a very important role in stabilizing the $\mathrm{N}_{6}$ ring. More recently, a $C 2 / m-\mathrm{CaN}_{3}$ structure containing the $\mathrm{N}_{6}$ ring has been reported, which has been also predicted in $\mathrm{LiN}_{3},{ }^{16,60} \mathrm{NaN}_{3},{ }^{21} \mathrm{MgN}_{3},{ }^{36}$ and $\mathrm{CaN}_{3} .{ }^{39}$ Moreover, the pressure effect on calcium azide might have a great impact in the rational design of potential polymeric nitrogen.

\subsection{Electronic structures}

To better understand the nature of the chemical bonding between two atoms and the formation mechanism of lowpressure $P \overline{1}-\mathrm{CaN}_{3}$ and high-pressure $C 2 / m-\mathrm{CaN}_{3}$, we have calculated their projected density of states (PDOS) at ambient pressure and high pressure $P=60 \mathrm{GPa}$ as shown in Fig. 4. We

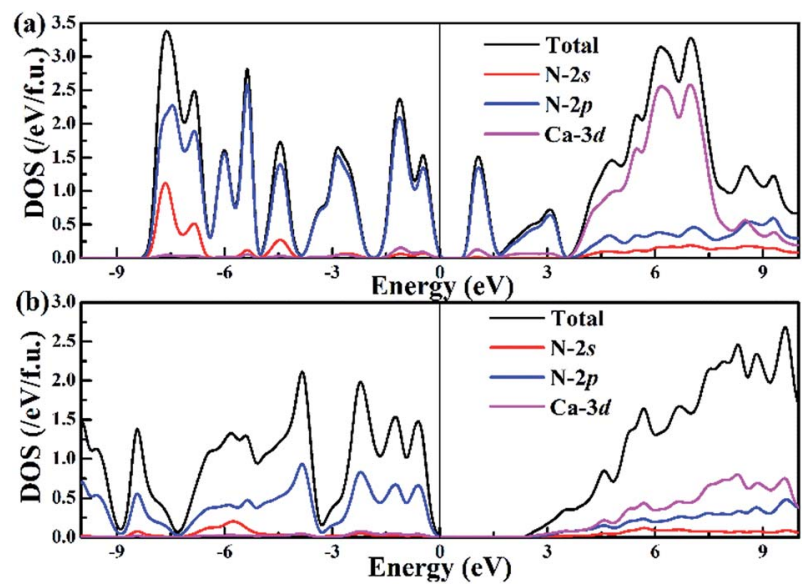

Fig. 4 Band structure and projected density of states of (a) $P 1-\mathrm{CaN}_{3}$ at ambient pressure and (b) $\mathrm{C} 2 / \mathrm{m}-\mathrm{CaN}_{3}$ at $60 \mathrm{GPa}$. 
can observe that $P \overline{1}-\mathrm{CaN}_{3}$ and $C 2 / m-\mathrm{CaN}_{3}$ are semiconductors characterized by an indirect band gap of $\sim 0.76 \mathrm{eV}$ and $\sim 2.38 \mathrm{eV}$, respectively. The atom-resolved DOS of the low-pressure $P \overline{1}$ $\mathrm{CaN}_{3}$ and high-pressure $C 2 / m-\mathrm{CaN}_{3}$ structures reveal that the densities of states near Fermi levels are primarily originated from the $\mathrm{N}$ orbital electrons. In the " $\mathrm{N}_{6}$ " chain of $P \overline{1}-\mathrm{CaN}_{3}$ (Fig. 3a), all $\mathrm{N}$ atoms are $\mathrm{sp}^{2}$-hybridized, forming five $\mathrm{N}-\mathrm{N} \sigma$ bonds with neighboring $\mathrm{N}$ atoms and six lone pairs. The $\mathrm{sp}^{2}$ hybridized orbitals of the four central $\mathrm{N}$ atoms in the " $\mathrm{N}_{6}$ " chain form two $\sigma$ bonds with the $\mathrm{sp}^{2}$-hybridized orbital located at both $\mathrm{N}$ atoms at each side. The remaining $\mathrm{sp}^{2}$-hybridized orbitals at four central $\mathrm{N}$ atoms as well as the two $\mathrm{sp}^{2}$-hybridized orbitals at both terminal $\mathrm{N}$ atoms are filled and form lone pairs. Therefore, all of the bonding states and lone pair states are filled and all of the anti-bonding states are unoccupied in $P \overline{1}$ $\mathrm{CaN}_{3}$, leading to a semiconductive state. The strong covalent bondings between different inequivalent $\mathrm{N}$ atoms and the lone pairs on the side $\mathrm{N}$ atoms are also revealed by the ELF (Fig. $5 \mathrm{a}$ ). This 6-membered ring with $10 \pi$-electrons in high-pressure $C 2 /$ $m$-CaN $\mathrm{N}_{3}$ follows the aromatic $4 n+2$ Hückel rule and it is similar to the well-known isoelectronic inorganic cyclic $\mathrm{S}_{3} \mathrm{~N}_{3}{ }^{-}$and $\mathrm{P}_{6}{ }^{4-}$ species. ${ }^{61}$ In case of $\mathrm{MgN}_{3}$, Yu et al. reported that three bonding $\pi$-molecular orbitals (MO) as well as two degenerated antibonding $\pi^{*}$-molecular orbitals in the $\mathrm{N}_{6}$ rings were fully occupied over the six $\pi$-levels, leading to only one $\pi$-bond delocalized over the 6 nitrogen atoms. ${ }^{62}$ Their electronic situation explains well the structural feature encountered in $\mathrm{N}_{6}{ }^{4-}$, in which the $\mathrm{N}-\mathrm{N}$ bonds are slightly stronger than the known $\mathrm{N}-\mathrm{N}$ single bonds. Thus, in $C 2 / m-\mathrm{CaN}_{3}$, an energy gap exists in between $\pi_{4}^{*}$ and $\pi_{5}^{*} \mathrm{MO}$ - top of the valence band and the empty $\pi_{6}^{*}$ MO-bottom of the conduction band; hence, it behaves as a semiconductor.

In addition, to study the impact of the partial occupation of $\mathrm{N}-2 \mathrm{p}$ orbital on the electronic properties, we calculated the charge of $\mathrm{Ca}$ and $\mathrm{N}$ atoms of $P \overline{1}-\mathrm{CaN}_{3}$ and $C 2 / m-\mathrm{CaN}_{3}$ based on Bader analysis. The Bader method is used to analyze the charge transfer by implementing an algorithm developed by Henkelman et al. ${ }^{47,48}$ The result reveals that the Ca atoms contribute almost $1.3 \mathrm{e}$ to the $\mathrm{N}$ atoms forming the charged " $\mathrm{N}_{6}$ " chain, which suggests that $P \overline{1}-\mathrm{CaN}_{3}$ has ionic characteristics in the chemical bonds. In the predicted $P \overline{1}-\mathrm{CaN}_{3}$ and $C 2 / m-\mathrm{CaN}_{3}$ crystal, the $\mathrm{Ca}$ atoms behave as electron donors, whose concentration strongly influences the $\mathrm{N}-\mathrm{N}$ bonding. This finding contributes to better understanding the chemical bonding behaviors.

(a)

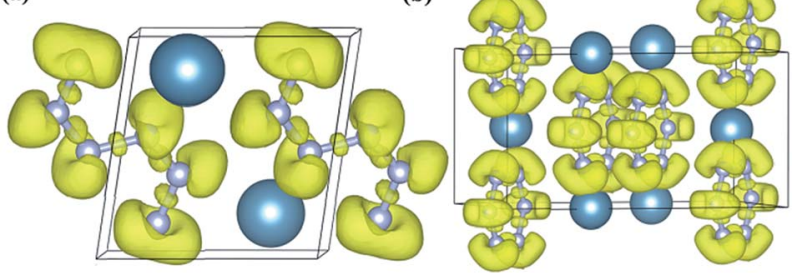

Fig. 5 The ELF distributions of (a) $P 1-\mathrm{CaN}_{3}$ at ambient pressure and (b) $\mathrm{C} 2 / \mathrm{m}-\mathrm{CaN}_{3}$ at $60 \mathrm{GPa}$. The value of isosurface is 0.75 .

\subsection{Chemical bonding}

Subsequently, in order to understand the bonding character of two $\mathrm{CaN}_{3}$ structures, the electronic localization function $(\mathrm{ELF})^{63}$ was calculated as shown in Fig. 5. For two $\mathrm{CaN}_{3}$ structures, the strong covalent bonding between nitrogen atoms and the lone pair electrons is revealed clearly by the ELF (Fig. 5). The large areas with the large ELF values between $\mathrm{N}$ and $\mathrm{N}$ atoms are shown in Fig. 5, which is typical of a strong covalent bonding. In the " $\mathrm{N}_{6}$ " chain of $P \overline{1}$ $\mathrm{CaN}_{3}$ shown in Fig. $1 \mathrm{~b}$, all $\mathrm{N}$ atoms are $\mathrm{sp}^{2}$-hybridized. For intermediate four $\mathrm{N}$ atoms, two $\mathrm{sp}^{2}$-hybridized orbitals form two $\mathrm{N}-\mathrm{N} \sigma$ bonds with neighboring two atoms. The remaining $\mathrm{sp}^{2}$-hybridized orbital of this $\mathrm{N}$ atom is filled and forms one lone pair. For bicephalous two $\mathrm{N}$ atoms, one $\mathrm{sp}^{2}$-hybridized orbital forms one $\sigma$ bond with the $\mathrm{sp}^{2}$-hybridized orbital of one neighboring $\mathrm{N}$ atom. The remaining two $\mathrm{sp}^{2}$-hybridized orbitals of the $\mathrm{N}$ atoms are filled and form lone pairs. The covalent bondings between different inequivalent $\mathrm{N}$ atoms and the lone pairs on the side $\mathrm{N}$ atoms are also revealed by the ELF (Fig. 5). Therefore, all of the bonding states and lone pair states are filled and all of the anti-bonding states are unoccupied in $P \overline{1}-\mathrm{CaN}_{3}$, leading to a semiconducting state.

To get further insight into the $\mathrm{N}-\mathrm{N}$ bonding information in the $P \overline{1}-\mathrm{CaN}_{3}$ compound, we performed crystal orbital Hamilton population (COHP) analysis. COHP can partition the bandstructure energy into the orbital-pair interactions and it is useful to indicate bonding, nonbonding, and antibonding contributions for the band-structure energy. Herein, the familiar COHP approach that stems from a plane-wave calculation was adopted and it was dubbed "projected COHP" (pCOHP). ${ }^{64,65}$ Then, we analyzed the COHP and integral COHP (ICOHP) to characterize the bonding nature of the $\mathrm{N}-\mathrm{N}$ pairs in $P \overline{1}-\mathrm{CaN}_{3}$. Fig. 6 shows that the nitrogen atom pairs with different distances exist in the form of the covalent bonds. The COHP plot of the N1-N3 pairs and N1-N5 pairs are shown in

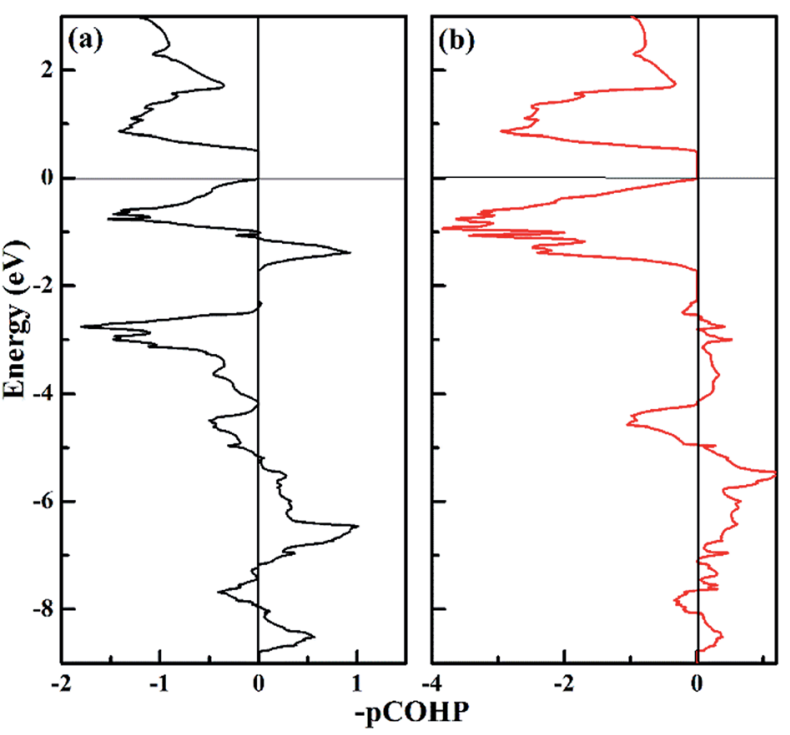

Fig. 6 Plot of COHP for $P$ 1- $\mathrm{CaN}_{3}$. The positive and negative COHP values denote bonding and antibonding interactions, respectively. (a) N1-N3 pairs separated by $1.34 \AA$. (b) N1-N5 pairs separated by $1.30 \AA$. 
Fig. $6 a$ and b, respectively. It is clear to see that the bonding states in $P \overline{1}-\mathrm{CaN}_{3}$ are fully occupied and the antibonding states are unoccupied, which can lead to the covalent bonding between two adjacent nitrogen atoms. The bonding strength based on counting the energy-weighted population of wave functions between two atomic orbitals in $P \overline{1}-\mathrm{CaN}_{3}$ can be expressed by the theoretical values of ICOHP. The values of ICOHP corresponding to those shown in Fig. 6 are listed in the order -4.243 and -3.044. It is shown that the interaction between N1-N5 nitrogen atoms is stronger than that between N1-N3 atoms. For highpressure $C 2 / m-\mathrm{CaN}_{3}$, all $\mathrm{N}$ atoms in the " $\mathrm{N}_{6}$ " ring are $\mathrm{sp}^{2}$ hybridized, two $\mathrm{sp}^{2}$-hybrid orbitals form two $\mathrm{N}-\mathrm{N} \sigma$ bonds with neighboring two atoms, and the remaining $\mathrm{sp}^{2}$-hybrid orbital of this $\mathrm{N}$ atom is filled and forms one lone pair. The single-bond feature can be inferred from the similar bond lengths and strengths of these $\mathrm{N}-\mathrm{N}$ bonds. As a potential high-energy-density material, the dissociation of $P \overline{1}-\mathrm{CaN}_{3}$ and $C 2 / m-\mathrm{CaN}_{3}$ is highly exothermic because of the existence of the single-bond feature.

\section{Conclusions}

In summary, the high-pressure polymeric nitrogen phase of $\mathrm{CaN}_{3}$ was explored using first-principles calculations up to a high-pressure of $100 \mathrm{GPa}$. One new monoclinic $P \overline{1}-\mathrm{CaN}_{3}$ was predicted to become energetically stable under low pressure. For the first time, we identified a novel phase featuring the charged " $\mathrm{N}_{6}$ " chain in the $P \overline{1}-\mathrm{CaN}_{3}$ structure. On further compression above $60 \mathrm{GPa}$, another monoclinic phase $\mathrm{C} 2 / \mathrm{m}$ $\mathrm{CaN}_{3}$ becomes the most thermodynamically stable phase and remains the lowest-enthalpy phase up to $100 \mathrm{GPa}$. Moreover, this new predicted high-pressure structure can be mechanically stable at ambient conditions, which may make an ambientpressure recovery possible. The nitrogen atoms are $\mathrm{sp}^{2}$-hybridized in the " $\mathrm{N}_{6}$ " chain and the " $\mathrm{N}_{6}$ " ring, which indicates that each $\mathrm{N}$ atom forms one or two $\sigma$ bonds with its neighboring $\mathrm{N}$ atoms, suggesting an exceptionally high content of the single $\mathrm{N}-\mathrm{N}$ bonds. The present study provides new insights into the understanding of polynitrogens and encourages the experimental exploration of these promising materials in the future.

\section{Conflicts of interest}

There are no conflicts to declare.

\section{Acknowledgements}

This work was supported by the National Natural Science Foundation of China (No. 11747003, 11404134), Jilin Provincial Science and Technology Development Project of China (20160520016JH). Project 2017005 supported by Graduate Innovation Fund of Jilin University.

\section{References}

1 Y. Li, J. Hao, H. Liu, S. Lu and J. S. Tse, Phys. Rev. Lett., 2015, 115, 105502.
2 Z. Raza, C. J. Pickard, C. Pinilla and A. M. Saitta, Phys. Rev. Lett., 2013, 111, 235501.

3 L. Andrews, M. Zhou, G. V. Chertihin, W. D. Bare and Y. Hannachi, J. Phys. Chem. A, 2000, 104, 1656-1661.

4 M. M. G. Alemany and J. L. Martins, Phys. Rev. B: Condens. Matter Mater. Phys., 2003, 68, 024110.

5 B. Hirshberg, R. B. Gerber and A. I. Krylov, Nat. Chem., 2014, 6, 52-56.

6 F. Zahariev, S. V. Dudiy, J. Hooper, F. Zhang and T. K. Woo, Phys. Rev. Lett., 2006, 97, 155503.

7 X. Wang, Y. Wang, M. Miao, X. Zhong, J. Lv, T. Cui, J. Li, L. Chen, C. J. Pickard and Y. Ma, Phys. Rev. Lett., 2012, 109, 175502.

8 F. Zahariev, A. Hu, J. Hooper, F. Zhang and T. Woo, Phys. Rev. B: Condens. Matter Mater. Phys., 2005, 72, 214108-6.

9 C. Mailhiot, L. H. Yang and A. K. McMahan, Phys. Rev. B: Condens. Matter Mater. Phys., 1992, 46, 14419-14435.

10 Y. Ma, A. R. Oganov, Z. Li, Y. Xie and J. Kotakoski, Phys. Rev. Lett., 2009, 102, 065501.

11 M. I. Eremets, A. G. Gavriliuk, I. A. Trojan, D. A. Dzivenko and R. Boehler, Nat. Mater., 2004, 3, 558-563.

12 J. Uddin, V. Barone and G. E. Scuseria, Mol. Phys., 2006, 104, 745-749.

13 F. Peng, Y. Yao, H. Liu and Y. Ma, J. Phys. Chem. Lett., 2015, 6, 2363-2366.

14 X. Huang, D. Li, F. Li, X. Jin, S. Jiang, W. Li, X. Yang, Q. Zhou, B. Zou, Q. Cui, B. Liu and T. Cui, J. Phys. Chem. C, 2012, 116, 9744-9749.

15 S. A. Medvedev, I. A. Trojan, M. I. Eremets, T. Palasyuk, T. M. Klapotke and J. Evers, J. Phys.: Condens. Matter, 2009, 21, 195404.

16 X. Wang, J. Li, J. Botana, M. Zhang, H. Zhu, L. Chen, H. Liu, T. Cui and M. Miao, J. Chem. Phys., 2013, 139, 164710.

17 M. I. Eremets, M. Y. Popov, I. A. Trojan, V. N. Denisov, R. Boehler and R. J. Hemley, J. Chem. Phys., 2004, 120, 10618-10623.

18 K. Ramesh Babu and G. Vaitheeswaran, Chem. Phys. Lett., 2013, 586, 44-50.

19 B. A. Steele and I. I. Oleynik, Chem. Phys. Lett., 2016, 643, 2126.

20 H. Zhu, F. Zhang, C. Ji, D. Hou, J. Wu, T. Hannon and Y. Ma, J. Appl. Phys., 2013, 113, 033511.

21 M. Zhang, K. Yin, X. Zhang, H. Wang, Q. Li and Z. Wu, Solid State Commun., 2013, 161, 13-18.

22 J. Hooper and E. Zurek, J. Phys. Chem. C, 2012, 116, 1332213328.

23 D. Hou, Phys. Rev. B: Condens. Matter Mater. Phys., 2011, 84, 064127.

24 D. Hou, F. Zhang, C. Ji, T. Hannon, H. Zhu, J. Wu, V. I. Levitas and Y. Ma, J. Appl. Phys., 2011, 110, 023524.

25 C. Ji, F. Zhang, D. Hou, H. Zhu, J. Wu, M.-C. Chyu, V. I. Levitas and Y. Ma, J. Phys. Chem. Solids, 2011, 72, 736739.

26 J. Li, X. Wang, N. Xu, D. Li, D. Wang and L. Chen, Europhys. Lett., 2013, 104, 16005.

27 J. Zhang, Z. Zeng, H.-Q. Lin and Y.-L. Li, Sci. Rep., 2014, 4, 4358. 
28 X. Wang, J. Li, H. Zhu, L. Chen and H. Lin, J. Chem. Phys., 2014, 141, 044717.

29 Z. Liu, D. Li, S. Wei, W. Wang, F. Tian, K. Bao, D. Duan, H. Yu, B. Liu and T. Cui, Inorg. Chem., 2017, 56, 7494-7500.

30 A. F. Goncharov, N. Holtgrewe, G. R. Qian, C. H. Hu, A. R. Oganov, M. Somayazulu, E. Stavrou, C. J. Pickard, A. Berlie and Y. Fei, J. Chem. Phys., 2015, 142, 648-651.

31 K. Yin, Y. Wang, H. Liu, F. Peng and L. Zhang, J. Mater. Chem. A, 2015, 3, 4188-4194.

32 A. Hu and F. Zhang, J. Phys.: Condens. Matter, 2010, 22, 505402.

33 J. Wang, L. Zhang, F. Long, W. Wang, Y. Gu, S. Mo, Z. Zou and Z. Fu, $R S C A d v$., 2016, 6, 23272-23278.

34 D. Li, F. Tian, Y. Lv, S. Wei, D. Duan, B. Liu and T. Cui, J. Phys. Chem. C, 2017, 121, 1515-1520.

35 Z. Raza, I. Errea, A. R. Oganov and A. M. Saitta, Sci. Rep., 2013, 4, 5889.

36 S. Wei, D. Li, Z. Liu, X. Li, F. Tian, D. Duan, B. Liu and T. Cui, Phys. Chem. Chem. Phys., 2017, 19, 9246-9252.

37 H. Wang, Y. Yao, Y. Si, Z. Wu and G. Vaitheeswaran, J. Phys. Chem. C, 2014, 118, 650-656.

38 Y. Zhang, W. Wu, Y. Wang, S. A. Yang and Y. Ma, J. Am. Chem. Soc., 2017, 139, 13798-13803.

39 S. Zhu, F. Peng, H. Liu, A. Majumdar, T. Gao and Y. Yao, Inorg. Chem., 2016, 55, 7550-7555.

40 J. Lv, Y. Wang, L. Zhu and Y. Ma, Phys. Rev. Lett., 2011, 106, 015503.

41 Y. Wang, J. Lv, L. Zhu and Y. Ma, Comput. Phys. Commun., 2012, 183, 2063-2070.

42 Y. Wang, J. Lv, L. Zhu and Y. Ma, Phys. Rev. B: Condens. Matter Mater. Phys., 2010, 82, 094116.

43 J. P. Perdew, K. Burke and M. Ernzerhof, Phys. Rev. Lett., 1998, 80, 891.

44 G. Kresse and J. Furthmüller, Phys. Rev. B: Condens. Matter Mater. Phys., 1996, 54, 11169-11186.

45 P. E. Blöchl, Phys. Rev. B: Condens. Matter Mater. Phys., 1994, 50, 17953-17979.
46 H. J. Monkhorst and J. D. Pack, Phys. Rev. B: Condens. Matter Mater. Phys., 1976, 13, 5188-5192.

47 G. Henkelman, A. Arnaldsson and H. Jónsson, Comput. Mater. Sci., 2006, 36, 354-360.

48 W. Tang, E. Sanville and G. Henkelman, J. Phys.: Condens. Matter, 2009, 21, 084204.

49 A. Togo, F. Oba and I. Tanaka, Phys. Rev. B: Condens. Matter Mater. Phys., 2008, 78, 134106.

50 S. Grimme, J. Comput. Chem., 2006, 27, 1787-1799.

51 T. Bŭcko, J. Hafner, S. Lebégue and J. G. Angyán, J. Phys. Chem. A, 2010, 114, 11814.

52 J. P. Prates Ramalho, J. R. B. Gomes and F. Illas, RSC Adv., 2013, 3, 13085.

53 C. J. Pickard and R. J. Needs, Phys. Rev. Lett., 2009, 102, 125702.

54 W. J. Evans, J. Lipp, C.-S. Yoo, H. Cynn, J. L. Herberg, R. S. Maxwell and M. F. Nicol, Chem. Mater., 2006, 18, 2520.

55 Z.-J. Wu, E.-J. Zhao, H.-P. Xiang, X.-F. Hao, X.-J. Liu and J. Meng, Phys. Rev. B: Condens. Matter Mater. Phys., 2007, 76, 054115.

56 E. D. Raczyńska, Comput. Theor. Chem., 2011, 971, 38-41.

57 M. N. Glukhovtsev and P. von Ragué Schleyer, Chem. Phys. Lett., 1992, 198, 547-554.

58 K. J. Wilson, S. A. Perera, R. J. Bartlett and J. D. Watts, J. Phys. Chem. A, 2001, 105, 7693-7699.

59 H.-X. Duan and Q.-S. Li, Chem. Phys. Lett., 2006, 432, 331335.

60 M. Zhang, H. Yan, Q. Wei, H. Wang and Z. Wu, Europhys. Lett., 2013, 101, 26004.

61 C. W. Allen, RSC Pub., 2009, 17031-17032.

62 S. Yu, B. Huang, Q. Zeng, A. R. Oganov, L. Zhang and G. Frapper, J. Phys. Chem. C, 2017, 121, 11037-11046.

63 A. D. Becke and K. E. Edgecombe, J. Chem. Phys., 1990, 92, 5397.

64 V. L. Deringer, A. L. Tchougréeff and R. Dronskowski, J. Phys. Chem. A, 2011, 115, 5461-5466.

65 S. Maintz, V. L. Deringer, A. L. Tchougréeff and R. Dronskowski, J. Comput. Chem., 2013, 34, 2557-2567. 